\title{
EUGENIO COSERIU E A LINGUÍSTICA DO TEXTO NO BRASIL
}

\author{
EUGENIO COSERIU AND TEXT LINGUISTICS IN BRAZIL
}

\author{
Clemilton Lopes Pinheiro ${ }^{1}$
}

RESUMO: As primeiras pesquisas sobre o texto, no Brasil, surgiram no início da década de 1980, quando apareceram as primeiras publicações que apresentaram ao leitor brasileiro uma visão geral do que se estudava na Europa sobre o tema, sobretudo em países como Alemanha e França. Atualmente, os estudos do texto no país estão consolidados, ainda sob a influência de autores europeus, mas buscam sua identidade. O nome de Eugenio Coseriu fui silenciado, no Brasil, nesse campo. Sem querer discutir as razões desse desinteresse dos pesquisadores que impediu a influência de Coseriu nos estudos do texto no Brasil, propomos, neste trabalho, uma reflexão sobre duas perspectivas do programa de pesquisa sobre o texto desenvolvida no país: a Perspectiva textual-interativa e a Perspectiva sociocognitivo-discursiva. Para isso, tomaremos como base a distinção coseriana entre gramática do texto e linguística do texto.

PALAVRAS-CHAVE: Coseriu; Linguística no Brasil; Texto.

ABSTRACT: The first researches on the text in Brazil emerged in the early 1980s, when the first publications presented to Brazilian reader an overview of what was being studied in Europe on the subject, especially in countries such as Germany and France. Currently, studies of the text in the country are consolidated, still under the influence of European authors, but seek their identity. The name of Eugenio Coseriu was silenced in Brazil in this field. Without to discuss the reasons for this lack of interest of the researchers that prevented the influence of Coseriu in the studies of the text in Brazil, we propose, in this work, a reflection about two perspectives of the research program on the text developed in the country (Textual-interactive perspective and Sociocognitive-discursive perspective) taking into account the Coserian distinction between text grammar and text linguistics.

KEYWORDS: Coseriu; Linguistics in Brazil; Text.

\section{Introdução}

Eugenio Coseriu nasceu em 1921, na Romênia. Depois de seus estudos na Romênia e Itália, ele se tornou professor de linguístca geral e indo-europeia, na Universidade de Montevidéu. Em 1963, foi nomeado professor de linguística romana e geral, em Tübingen, Alemanha.

\footnotetext{
${ }^{1}$ Professor de Linguística no Programa de Pós-Graduação em Estudos da Linguagem na Universidade Federal do Rio Grande do Norte.
} 
Coseriu desenvolveu os princípios fundamentais de sua teoria da linguagem com base ainda na linguística estrutural, mas dominou quase todas as áreas temáticas da linguística geral e uma quantidade notável de estudos filológicos de línguas particulares.

A lista de suas publicações abrange quase todos os setores da linguística: a filosofia da linguagem, a teoria da linguagem, a metodologia da linguística, a fonologia, a teoria gramatical, a semântica, a linguística de texto, a dialetologia, a sociolinguística, a estilística, a história da teoria da tradução, a política linguística, a história da linguística.

O autor utilizou o termo linguística textual pela primeira vez em meados dos anos 1950 em um artigo que escreveu em espanhol: Determinación y entorno. De los problemas de una linguística del hablar ${ }^{2}$. Mais tarde, no início da década de 1980, o pensamento de Coseriu sobre o texto foi apresentado na obra Textlinguistik. Eine Einführung, editada por Jörn Albrecht (COSERIU, 1980), a partir de um curso ministrado na Universidade de Tübingen. O livro, traduzido para o italiano (COSERIU, 1997) e para o espanhol (COSERIU, 2007), é dedicado inteiramente ao texto. Em suma, trata-se de uma investigação sobre o texto concebido como tal, em uma época de transição entre o período de formação e consolidação de uma ciência do texto.

O nome de Eugenio Coseriu é praticamente silenciado no Brasil no campo dos estudos do texto. As pesquisas sobre o texto, no país, surgiram nos primeiros anos da década de 1980, quando apareceram as primeiras publicações que apresentam ao leitor brasileiro uma visão geral sobre o que se estudava na Europa, sobretudo em países como Alemanha e França. Na fase atual, os estudos sobre o texto, no Brasil, estão consolidados a partir dessa influência de autores europeos, mas têm, pouco a pouco, assumido sua identidade. Segundo nosso ponto de vista, acreditamos que a linguística textual, no Brasil, tem se caracterizado como uma área que focaliza o texto a partir de interesses variados e apresenta uma forte inclinação para a interdisciplinaridade. Nesse sentido, o programa de pesquisa brasileiro tende a se organizar em torno de parâmetros do texto (referenciação, coerência, sequências, argumentação, topicalidade, dentre outros) (CAVALCANTE et al., 2015). Ao focalizarem determinados parâmetros do texto, os pesquisadores assumem diferentes abordagens teóricas. Entre essas diferentes abordagens, duas delas parecem estar mais diretamente associadas ao trabalho teórico próprio de pesquisadores brasileiros: a Perspectiva textual-interativa e a Perspectiva

\footnotetext{
${ }^{2}$ Publicado em português (COSERIU, 1979).
} 
sociocognitivo-discursiva. Por esse motivo, resolvemos refletir sobre elas, tomando como base a distinção coseriana entre gramática do texto e linguística do texto.

Essas perspectivas não fazem referência aos pressupostos teóricos de Eugenio Coseriu, e foram concebidas em contextos histórico-acadêmicos bem distintos. No entanto, acreditamos ser possível estabelecer um diálogo entra elas. O nosso objetivo, portanto, é tentar observar pontos de convergência e divergência entre essas abordagens, e, dessa forma, contribuir com a ampliação e o aprofundamento dos estudos do texto.

\section{A linguística do texto na perspectiva de Coseriu}

O ponto de partida de Coseriu para o estudo do texto é a sua proposta de que a linguagem apresenta três níveis autônomos: 1) o nível universal ou nível do falar em geral; 2) o nível histórico das línguas; 3) o nível individual dos textos (COSERIU, 2007).

O nível universal diz respeito aos fenômenos comuns a todas as línguas. A primeira propriedade universal das línguas é seu caráter sígnico, ou seja, a possibilidade de referir-se a algo que não se identifica com ela mesma. A comparação entre as línguas fornece uma evidência para essa propriedade: diferentes línguas correspondem a configurações distintas para uma mesma realidade extralinguística. Algumas atividades relacionadas à linguagem, como a tradução, por exemplo, só são possíveis a partir do pressuposto de que diferentes línguas podem referir-se a uma mesma realidade e o fazem de forma diferenciada. A segunda propriedade que Coseriu atribui ao nível universal da linguagem é a faculdade universal de falar, não determinada historicamente. "Trata-se de um saber falar que não coincide simplesmente com o saber falar alemão, francês etc., mas que vale para toda língua e para todo falar" (COSERIU, 2007, p. 131) $)^{3}$.

O segundo nível autônomo do falar é o nível histórico das línguas. Cada língua particular dispõe de um léxico estruturado de forma diferente, possui sua própria gramática e seu sistema fonológico. Esse nível, portanto, compreende uma língua concreta e seus processos de significação.

O terceiro nível é o individual, ou seja, o plano do contéudo próprio e exclusivo do texto. Para sustentar a autonomia do nível dos textos em relação ao nível universal e

\footnotetext{
${ }^{3}$ As citações originais de Coseriu (2007) estão em espanhol. Tradução nossa.
} 
histórico, Coseriu assinala, principalmente, o fato de que as regras da língua podem ser suspensas no texto sem provocar rejeição, e de que os textos são influenciados pelos universos de discurso - o que não acontece com as línguas - e têm tradições particulares, diferentes das tradições das línguas históricas.

Nessa proposta, Coseriu distingue, portanto, duas formas de conceber o texto: o texto como nível autônomo da linguagem e o texto como nível de estruturação idiomática, superior à oração, ao sintagma, à palavra e aos elementos mínimos portadores de significado. Consequentemente, o autor também delineia duas formas de linguística do texto, para ele, cientificamente legítimas: a que concebe o texto como nível da linguagem em geral e a que concebe o texto como um nível de estruturação das línguas. Ambas as modalidades não são nem contrárias nem excludentes, mas complementares e integradas, pois se encontram em distintos planos do linguístico: o propriamente idiomático e o individual.

\begin{abstract}
Inicialmente, dois tipos de linguística de texto podem ser distinguidos. O objetivo do primeiro são os textos como um nível autônomo da linguagem, independente da língua em que se expressa. Essa linguística do texto seria $a$ linguística do texto propriamente dita (...). O segundo tipo de linguística do texto toma como objeto o texto enquanto nível de estruturação idiomática. Por isso, e também em benefício da clareza terminológica, se denominará gramática do texto ou gramática trans-oracional (também análise transoracional ou transfrástica) (COSERIU, 2007, p. 116-17).
\end{abstract}

A linguística do texto como ciência do nível individual do falar consiste, para Coseriu, antes de tudo, na explicação do sentido de cada texto, isto é, uma hermenêutica do sentido. No que diz respeito à teoria hermenêutica, o autor não se refere a nenhuma em particular. Hermenêutica, para ele, significa, de início, compreensão e interpretação do caráter individual do texto em relação aos outros níveis da linguagem. Por sua vez, a gramática do texto deve estudar os procedimentos estritamente idiomáticos para a construção dos textos.

Coseriu assinala que, no âmbito dessa linguística do texto idiomática, muitos trabalhos relevantes têm sido desenvolvidos nos últimos anos - últimos anos da década de 80 -, mas reconhece também que "o elevado nível técnico da investigação realizada nem sempre corresponde a uma delimitação téorica suficientemente clara do objeto que se deseja investigar" (2007, p. 306). Concretamente, nos dois tipos de linguística do texto, o texto é o mesmo, apenas é considerado de modo distinto: nível autônomo da linguagem (linguística do texto propriamente dita) ou nível de estruturação idiomática (gramática textual). 
Ao comprovar e justificar o sentido dos textos particulares, a linguística do texto propriamente dita só pode chegar a um tipo de generalização: a identificação de universais empíricos, ou seja, de características comuns a vários textos (ou até mesmo a todos os textos). Ao buscar as generalizações acerca das formas que o sentido assume nos textos, essa linguística do texto pode ser identificada com a teoria da investigação das classes de textos. Essa abordagem não coincide simplesmente com a dos gêneros, mas a engloba.

Assim, a linguística que concebe o texto como nível individual da linguagem prevê três tarefas para a abordagem o texto: a) indicação da posição dos textos na esfera do linguístico (teoria dos textos), b) construção de uma lista de procedimentos textuais possíveis para a construção do sentido e a delimitação desses procedimentos em relação a outros (linguística do texto geral), e c) descrição e interpretação de um determinado texto, incluído, a exposição da história desse texto (linguística do texto). Segundo Lamas (2007, p. 52), essa linguística é "três vezes linguística do texto":

Os textos são fatos individuais, mas não absolutamente singulares, pois apresentam, ademais, uma dimensão universal, que inclue os traços da textualidade, e uma dimensão histórica que faz que compartihem tradições e modos expressivos; dito de outro modo, a linguística do texto deve explicar, primeiro, o que é um texto em geral e como se configura, segundo, os traços que distintos textos compartilham e que funçõem exercem no falar, e terceiro, o que significa - em toda a extensão da palavra - um dado texto em dada situação ${ }^{4}$.

Coseriu (2007) parece focalizar a terceira tarefa, ou seja, a confirmação e a justicativa do sentido como um aspecto inerente a qualquer texto, escrito ou falado em qualquer língua. $\mathrm{O}$ autor defende que há diferentes processos e contextos que contribuem para a produção e a interpretação do sentido. Esses processos e contextos se expressam de forma objetiva no texto, consequentemente, eles são recuperáveis objetivamente. Aschenberg (2015), a partir da leitura de Coseriu (2007), sintetiza uma séries de categorias que a linguística textual deve desenvolver para identificar os processos e os contextos da produção e interpretação do sentido.

- categorias que resultam de interpretações concretas: as interpretações tomadas como modelos mostram os processos individuais dos textos e são consideradas ao mesmo tempo como procedimentos potenciais da consituiçao do sentido, e por, consequência, como critérios de análise no quadro de uma heurística geral;

- categorias semiológicas: a análise das relações textuais do signo no nível do significante (relações materiais) e no nível do significado (relações semânticas no sentido largo) desenvolve as categorias da interpretação semiológica do texto;

\footnotetext{
${ }^{4}$ Citação original em espanhol. Tradução nossa.
} 
- categorias dos entornos: o panorama de diferentes tipos de contexto intratextuais e extratextuais estabelece os entornos que contribuem à geração/compreensão do sentido. (ASCHENBERG, 2015, p. 213) ${ }^{5}$.

Um ponto que merece destaque nessas categorias é o entorno. Coseriu (2007) retoma alguns trabalhos sobre a questão e apresenta um quadro extremente detalhado e sistemático. Ao abordar o problema dos entornos, Coseriu (2007) afirma que o texto só pode significar e ser interpretado fora do que ele diz, para além da materialidade linguística, graças às atividades expressivas complementares que são atividades nãoverbais, entre as quais se encontram principalmente as circunstâncias da fala, "os entornos". Coseriu (2007) propõe a existência de quatro tipos de entornos: a situação, a região, o contexto e o universo de discurso.

A situação são "as circunstâncias e as relações de espaço e tempo que se produzem pela própria fala" (p. 220). A região é definida com base no espaço "em cujos limites um signo funciona em determinados sistemas de significação" (p. 214). O entorno região é subdividido em zona, âmbito e ambiente.

O contexto pode ser verbal ou extra verbal. Esse último comporta ainda subtipos: físico ("constituído pelas coisas que estão à vista de quem fala ou as que o signo representa imediatamente"), empírico ("constituído por objetos e por estados de coisas objetivos conhecidos pelos interlocutores em um momento e em um lugar determinado") e natural (“designa a totalidade do mundo que nos é conhecido enquanto contexto verbal") (COSERIU, 2007, p. 224). Esses contextos compõem igualmente o conhecimento enciclopédico e são definidos a partir do sujeito.

Por fim, os universos do discurso compõem o "sistema universal de significações ao qual pertence um discurso (ou um enunciado) e que determina sua validade, seu sentido" (p. 221). Os textos que representam não apenas os diferentes universos (a religião, a ciência, a mitologia etc), mas também seus sistemas de saber e de valores.

Segundo Lamas (2007, p. 63-64) essa linguística do texto de Eugenino Coseriu é "sem dúvida, original":

Em nada ou em muito pouco se parece com outras "introduções" publicadas naqueles anos, pois tem mas de poética, de semiótica e de teoria da tradução que de gramática do texto, e tem mais de estilística que de teoria da comunicação e de pragmática. Essa originalidade é em si um valor, que, porém, tem um preço: o valor pode ser visto no contínuo desenvolvimento

\footnotetext{
${ }^{5}$ Citação original em francês. Tradução nossa.
} 
dos conceitos, inclusive o de texto; o preço é sua limitada recepção em círculos mais amplos $(\ldots)^{6}$.

Coseriu (2007) também procura esboçar categorias e princípios para dar conta das regras de uma língua determinada que atuam na construção do texto. Essas regras ultrapassam o limite da frase ou estão fora dos seus limites, e constituem o objeto da linguística que concebe o texto como nível de estruturação das línguas ou da gramática transfrástica. Essas categorias, que determinam relações existentes entre os diversos níveis da língua ou em apenas um nível, são a superordenação, a subordinação, a coordenação e a substituição.

A subordinação está relacionada ao fato de que um elemento de um nível inferior pode substituir o de um nível superior. Essa categoria não se aplica ao nível do texto, porque o texto é o último dos níveis da língua.

A subordinação se opõe à superordenação. No caso da subordinação, uma unidade de um nível superior funciona como outra do nível inferior. No nível do texto, Coseriu (2007) ilustra a subordinação com a integração de un discurso em outro, como ocorre com as citações, o discurso direto e o indireto. Cada língua dispõe de procedimentos específicos para esses casos.

Por meio da coordenação, unidades do mesmo nível se unem para formar unidades mais complexas. Da mesma forma, cada língua possui procedimentos particulares para esse tipo de relação.

O quarto tipo, a substituição, assume um papel central nas introduções à linguística textual, porque contribui em alto grau para a coesão e a coerência do texto, e porque representa uma relação transfrástica importante. Coseriu (2007) considera a sustituição como um procedimento anafórico ou catafórico que funciona em todos os níveis, desde os elementos mínimos até os textos. Assim podemos nos referir a um texto completo retomando-lo por meio das partículas não e sim. Um meio de sustituição econômico e de uso muito frequente é a pronominalização. Outras posibilidades são os diversos modos de retomar un elemento lexicalmente.

Como a gramática se refere aos procedimentos semântico-gramaticais das línguas concretas, o saber gramatical se situa no nível histórico, e contêm as regras de uma língua particular para a estruturação do texto, sem considerar as circunstâncias de emprego. Segundo Coseriu (2007, p. 338), “nenhuma língua conta até agora com uma exposição coerente e completa da gramática que vai além da sintaxe da oração, isto é,

\footnotetext{
${ }^{6}$ Citação original em espanhol. Tradução nossa.
} 
da gramática transoracional”. Essa gramática deve prever duas tarefas: a) identificação e descrição do que funciona sistematicamente para a estruturação do texto, as oposições necessárias (regulares) e as relações sintagmáticas, b) dentro dessa funções identificar o que é usual em cada língua. Embora não corresponda a sua própria concepção de linguística textual, para Coseriu a gramática transfrástrica "é uma ciência auxiliar indispensável para a linguística do texto" (COSERIU, 2007, p. 322).

\section{Perspectiva textual-interativa}

A Perspectiva textual-interativa (PTI), como proposta teórica para a análise textual, foi desenvolvida pelo grupo do texto do Projeto Gramática do Português Falado (PGPF), no Brasil. A base dessa perspectiva é o conceito de linguagem como interação, como atividade verbal impregnada pelo contexto espaço-temporal e sócio histórico em que os interlocutores se relacionam. A interação verbal é vista como resultado do exercício de uma competência comunicativa, que se manifesta na contingência da efetivação da atividade linguística do sujeito e é caracterizável a partir de regularidades, observáveis no texto e nas operações envolvidas em sua produção, que evidenciam um sistema de desempenho linguístico constituído de vários subsistemas: o fonológico, o morfossintático e o textual. Através dos dados presentes no texto, é possível identificar os indícios do modo de funcionamento desse sistema de desempenho (JUBRAN, 2006).

Com base na postulação desse sistema de desempenho linguístico, em que as estruturas linguísticas e as suas formas de processamento se integram num só conjunto, o enfoque textual-interativo concebe, então, o texto como fenômeno simultaneamente estruturado e emergente. A partir disso, postula-se que os dados pragmático-situacionais se inserem no texto, de forma que o interacional é inerente ao linguístico.

\footnotetext{
Nesse sentido, os dados pragmáticos não são vistos como moldura dentro da qual se processa o intercâmbio lingüístico, ou como camada de enunciação que envolve os enunciados. As condições comunicativas que sustentam a ação verbal inscrevem-se na superfície textual, de modo que se observam marcas do processo formulativo-interacional na materialidade lingüística do texto. (JUBRAN, 2006, p. 29).
}

Seguindo o percurso de análise que toma o texto como objeto global, para dele serem depreendidas regularidades configuradoras das estruturas e das formas de processamento das estratégias de composição, e inferidas funções pragmáticas relativas 
a essas estratégias, o grupo do texto do PGPF desenvolveu uma série de estudos que dizem respeito às atividades de formulação e elaboração do texto (no caso, especificamente do texto falado). Essas atividades de formulação e elaboração, interacionalmente situadas, são, então, entendidas como os processos de construção do texto.

No âmbito do PGPF, a noção de construção interacional do texto está intimamente ligada às contingências próprias da construção do texto falado. Os processos descritos são os decorrentes da relação entre planejamento verbal e realização linguística, e os fatores interacionais mais considerados são aqueles específicos da coprodução textual realizada no status nascendi do texto. Como o enfoque textualinterativo foi pensado especificamente para descrever as regularidades de construção do texto falado, pode-se ter a impressão de que o princípio segundo o qual os fatos formulativo-interacionais estão imersos na materialidade linguística do texto se aplica apenas a textos falados. No entanto, o conceito de texto como unidade globalizadora, sócio comunicativa, que ganha existência dentro de um processo interacional, é comum a textos falados e escritos (PINHEIRO, 2005). As marcas do processo formulativointeracional se materializam, então, tanto em textos falados como escritos. Dessa forma, os chamados processos construção de que trata a perspectiva são comuns tanto a textos falados como escritos, embora se reconheça também as especificidades de cada uma das modalidades.

Em síntese, essa perspectiva propõe que a análise da construção do texto seja integrada a fatores enunciativos "que lhe dão existência e se mostram na sua própria constituição" (JUBRAN, 2007, p. 312). Em termos operacionais, a análise é desenvolvida em termos das seguintes tarefas: a) definir regularidades/princípios de processamento dos procedimentos de construção textual; b) investigar as marcas formais que sistematicamente assinalam tais procedimentos; c) verificar a funcionalidade desses procedimentos em situações concretas de uso da linguagem, respeitado sempre o princípio de projeção conjugada, porém em graus diferentes e proporcionalmente correlacionados, das funções textual e interacional. (JUBRAN, 2007). São concebidos como procedimentos de construção textual diferentes fatos, de natureza diversa: macro categorias que particularizam diferentes tipos e gêneros de textos, organização tópica do texto, mecanismos de articulação na progressão textual, estratégias de referenciação, de inserção (parentetização), de reformulação (repetição, correção, parafraseamento) (JUBRAN e KOCH, 2016). 
Como já dissemos, essa perspectiva se insere em um projeto maior, o da elaboração de uma gramática, ou seja, a PTI foi pensada para atender uma demanda de descrição do subsistema textual: descrever as regularidades relativas a estratégias de construção textual. Essa característica contextual da perspectiva leva-nos, a princípio, a pensar que ela atende às tarefas de uma gramática textual, conforme prevê Coseriu (2007): identificar e descrever o que funciona sistematicamente para a estruturação do texto, e verificar o que é usual no português. No entanto, entendemos que não é possível fazer essa afirmação de forma tão categórica.

Não se percebe, na literatura relacionada à área, nenhuma referência às ideias de Eugenio Coseriu, seja em relação ao conceito de texto seja em relação ao conceito de gramática. No entanto, é possível perceber alguma relação com a proposta do autor. A proposta de gramática textual da PTI se insere em uma perspectiva comunicativa, que considera os textos reais, efetivamente produzidos, em diferentes situações de interação, e permite refletir sobre a maneira como são construídos. O texto, portanto, é uma unidade radicalmente distinta da frase e deve ser estudado como tal, para serem identificadas as propriedades e os traços que lhes são próprios.

De fato, o propósito central da PTI é explicar uma função, definida por motivos contextuais, em razão, evidentemente, do fato de se inserir em um projeto mais amplo de elaboração de uma gramática. A noção de contexto está relacionada às contingências da situação, muitas das quais próprias do texto falado, como as intenções do locutor e sua relação com seu interlocutor, e as característica do próprio ato comunicativo. Essas contingências são marcadas no texto, e a análise textual visa a articular estrutura (fenômenos de formulação e composição textual) e contexto (fenômenos da situação de comunicação).

Nas análises textual-interativas, não se faz referência explícita à construção de sentido, mas propõem uma lista de procedimentos textuais e delimitam cada um em relação ao outro. Da mesma forma, discutem a posição do texto na esfera do linguístico. Essas duas características parecem estar alinhadas às tarefas da linguística do texto coseriana que concebe o texto como nível individual da linguagem ${ }^{7}$. Por outro lado,

\footnotetext{
${ }^{7}$ Fazemos essa constatação com na leitura dos trabalhos, reunidos em Jubran e Koch (2006), sobre parentização, organização tópica, correção, paráfrase.
} 
outras análises focalizam a tarefa de identificar as regras de construção do texto usuais no português ${ }^{8}$.

Observamos, portanto, que a PTI, considerando o que diz Coseriu (2006, p. 320), "se apresenta, ao mesmo tempo, como parte da gramática de um idioma e como ciência do texto em geral". Segundo o autor, trata-se de um "programa irrealizável e carente de sentido", pois mobiliza diferentes fenômenos, "competências diferentes".

O nível idiomático se refere ao âmbito das regras de uma determinada língua: esta competência linguística pode deixar suspensas as regras da competência idealmente anterior. O nível expressivo diz respeito ao falar dentro de uma determinada situação, ou seja, à organização de atos linguísticos, certamente sobre a base - e em parte, com os meios, de outras competências, mas, não obstante, com independência delas. (COSERIU, 2007, p. 320).

Apesar da falta de distinção do que é histórico e do que é individual, nos parece, por outro lado, que a PTI aponta para a cooperação entre as duas linguísticas do texto. A abordagem do texto na perspectiva da estrutura do português (plano da expressão) e na perspectiva da articulação do sentido (plano do conteúdo) parece responder à questão “em que medida contribui o idiomaticamente 'correto' ao 'apropriado' da expressão?" (COSERIU, 2007, p. 322). A tarefa da PTI de verificação das marcas formais e da funcionalidade de procedimentos de construção textual em situações concretas de uso da linguagem, respeitado princípio de projeção conjugada das funções textual e interacional, ao nosso ver, sinaliza, embora indiretamente, para o cumprimento da “exitosa cooperação dessas duas disciplinas" (COSERIU, 2007, p. 322).

\section{Perspectiva sociocognitivo-discursiva}

Aqui, estamos entendendo por Perspectiva sociocognitivo-discursiva a base que fundamenta, de forma geral, algumas análises textuais praticadas no Brasil ${ }^{9}$. Como revela o próprio nome, essa perpectiva parte da relação de mútua constitutividade entre texto, discurso e sociocognição, e propõe que os processos de produção e interpretação do texto "estão profundamente enraizados na dinâmica sociocognitiva e discursiva da interação" (CAVALCANTE, PINHEIRO, LIMA e LINS, 2010, p. 233). Nesse sentido,

\footnotetext{
${ }^{8}$ Ver o trabalho sobre marcadores discursivos e sobre as marcas de parentização, também em Jubran e Koch (2006).

${ }^{9}$ Convém assinalar que essas análises são praticadas principalmente no âmbito do grupo de pesquisa PROTEXTO, coordenado pela professora Mônica Magalhães Cavalcante, na Universidade Federal do Ceará. http://www.protexto.ufc.br/
} 
o texto é concebido como um evento altamente complexo de produção de sentido, ratificando a proposta de Koch (2010, p. 33).

\begin{abstract}
O texto passa a ser considerado o próprio lugar da interação e os interlocutores, sujeitos ativos que - dialogicamente - nele se constroem e por ele são construídos. A produção de linguagem constitui atividade interativa altamente complexa de produção de sentidos que se realiza, evidentemente, com base nos elementos linguísticos presentes na superfície textual e na sua forma de organização, mas que requer não apenas a mobilização de um vasto conjunto de saberes (enciclopédia), mas a sua reconstrução e a dos próprios sujeitos - no momento da interação verbal.
\end{abstract}

Segundo Cavalcante, Brito, Custódio Filho e Silva (2016, p. 12), essa perspectiva deve também ser vista como "uma proposta, de alcance multidisciplinar, que advoga em favor da intrínseca relação entre pensamento, linguagem, cultura, situação de comunicação e discurso". Nesse sentido, os autores defendem a interferência do aparato discursivo, vinculado à sociocognição, na configuração textual. Por sociocognição assumem o pressuposto da cognição incorporada e situada segundo o qual “o conhecimento, no que diz respeito à produção e ao processamento, está vinculado a mecanismos institucionais de controle que, além de regularem as situações comunicativas em termos do que pode ser dito por quem, afetam diretamente a bagagem cognitiva dos sujeitos" (CAVALCANTE, BRITO, CUSTÓDIO FILHO, e SILVA, 2016, p. 11-12).

Essa perspectiva tem determinado o direcionamento de muitas investigações de diferentess fenômenos textual-discursivos, no Brasil. Não se trata, no entanto, de um modelo de análise, mas de um pressuposto que fundamenta a análise de configurações textuais e de processos de produçao de sentido. Cavalcante, Brito, Custódio Filho e Silva (2016) enumeram alguns "critérios de análise", que, embora já estejam consolidados pela tradição, impulsionam a análise sociocognitivo-discursiva.

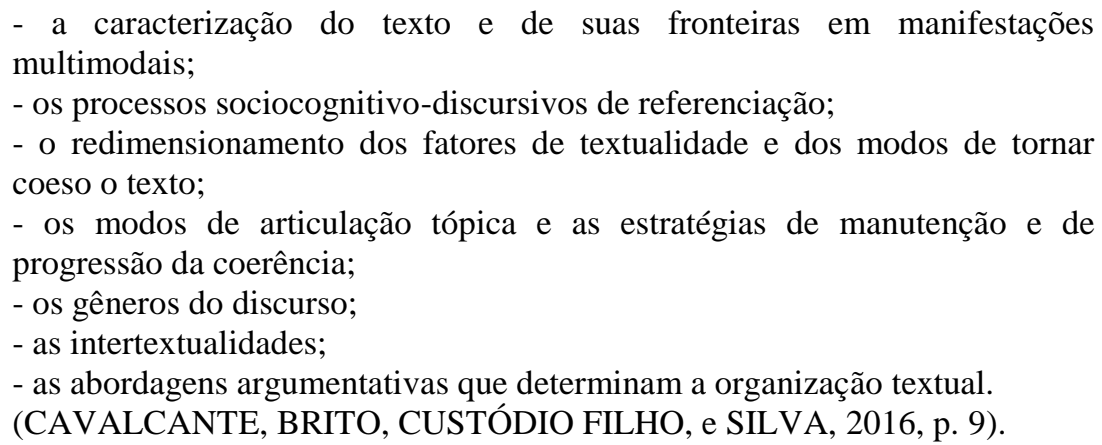

Da mesma forma como acontece com a PTI, os autores que vêm desenhando e desenvolvendo trabalhos a partir dos princípios teórico-metodológicos da Perspectiva 
sociocognitivo-discursiva não fazem nenhuma referência explícita a Eugenio Coseriu. No entanto, é impossível não perceber uma série de convergências entre as propostas. Uma primeira convergência diz respeito à própria concepção de texto. Ambas as propostas tomam o texto como uma unidade comunicativa completa e complexa, que é a base do uso da linguagem, e o estudo do texto tem como objetivo a confirmação e a justificação do sentido.

A forma de conceber e tratar o sentido também é um ponto de convergência. $O$ sentido é tomado como um aspecto inerente ao texto, e é resultado da fusão de funções linguísticas e extralinguísticas. Para Coseriu, uma proposta para as funções extralinguísticas é desenvolvida na teoria dos entornos. Para a Perspectiva sociocognitivo-discursiva é o contexto sociocognitivo, ou seja, "o conjunto de saberes ou conhecimentos prévios sobre a linguagem e sobre o mundo de forma geral, os quais se reconstroem na interpretação negociada dos enunciados" (MATOS, BRITO e CAVALCANTE, 2016, p. 500).

A linguística do texto tal como concebida por Coseriu (2007) tem como tarefa principal analisar os procedimentos de construção do sentido e as categorias de sua interpretação. Aliada a essa tarefa, espera-se também a reflexão da posição do texto na esfera do linguístico e construção de uma lista de procedimentos textuais possíveis para a construção do sentido e a delimitação desses procedimentos em relação a outros. A análise textual de base sociocognitivo-discursiva focaliza parâmetros do texto, conforme a lista de "critérios de análise" proposta por Cavalcante, Brito, Custódio Filho e Silva (2016). Essa lista envolve tanto procedimentos (referenciação, articulação tópica) como fatos relacionados à posição do texto na esfera do linguístico (caracterização do texto e de suas fronteiras em manifestações multimodais).

A lista de critérios ultrapassa os procedimentos que produzem sentido e fatos relativos à posição do texto como nível individual da linguagem (gênero de texto e abordagens argumentativas). A partir desse ponto, percebemos um afastamento da proposta de Coseriu. Entram no foco de análise fenômenos de outra natureza, que não dizem respeito diretamente ao nível individual da linguagem (ao texto), mas apenas revelados pelo texto. O texto, nesse caso, não é tomado conceitualmente como uma unidade, mas como espécime, uma peça de acesso a outros fatos.

Nessa direção, podemos observar também que as análises de base sociocognitivo-discursivas ultrapassam a preocupação com a produção e a construção do sentido. É possível dizer, talvez, que essa preocupação é consequência de outras. Em 
muitos trabalhos, o foco é o funcionamento do procedimento em si. É o caso dos inúmeros estudos sobre referenciação desenvolvidos a partir dessa perspectiva. A maior preocuação desses estudos, a nosso ver, é explicar a construção de referentes ou objetos de discurso. Ao mostrar como "os referentes de um texto não se projetam como prédados de forma acabada, imutável e universal, mas existem enquanto produção sociocultural” (MATOS, BRITO e CAVALCANTE, 2016, p. 500), apenas indiretamente a explicação da construção de objetos de discurso responde à tarefa de justificar o sentido do texto.

Segundo Cavalcante, Brito, Custódio Filho e Silva (2016, p. 8), a linguística textual "tem, hoje, uma preocupação não apenas descritiva, mas, principalmente, interpretativa. $\mathrm{O}$ objetivo é privilegiar o texto, mas com vistas à dimensão das práticas discursivas, com um interesse especial pela produção e pela compreensão de sentidos veiculados por diversas semioses”. Os autores reconheçam que não compete à linguística textual explicar essas práticas discursivas no que concerne à hegemonia de poder e mudanças socias. De fato, não nos parece que isso é feito, mas muitos trabalhos, ao nosso ver, têm privilegiado não apenas o texto, mas bastante a dimensão das práticas discursivas. Nesse sentido, obervamos aí também um afastamento da linguística do texto coseriana.

\section{Considerações finais}

Atualmente, no Brasil, no que diz respeito aos estudos do texto, os pesquisadores mobilizam diferentes noções e conceitos de texto e estudam diferentes parâmetros textual-discursivos com diferentes objetivos. Todo esse conjunto de conhecimentos é agrupado sob o rótulo linguística textual ou linguística do texto. Nesse sentido, o pensamento de Coseriu sobre o quadro da linguística do texto tal como se apresentava, no final da década de 1980, parece-nos ainda atual. "O objeto da linguística do texto não foi ainda identificado com exatidão, pelo que, em certo sentido, linguística do texto não é mais que um nome sob o qual se reunem pontos de vista muito diversos".

Por outro lado, observamos o desenvolvimento de abordagens do texto que têm posto a discussão sobre a natureza e a concepção do objeto texto à frente de suas propostas teóricas. Neste trabalho, consideramos duas dessas abordagens, na nossa opinião, diretamente associadas ao trabalho teórico próprio de pesquisadores brasileiros: a Perspectiva textual-interativa e a Perspectiva sociocognitiva-discursiva. Nosso 
objetivo foi o de refletir sobre elas, tomando como base a distinção coseriana entre gramática do texto e linguística do texto. Constamos que, embora nenhuma delas faça referência aos pressupostos de Eugenio Coseriu, a primeira é uma proposta de linguística do texto geral (nível do texto), de um lado, e de uma proposta de gramática do texto (nível de estruturação idiomática do português brasileiro), de outro lado. A segunda se desenvolve para ser uma linguística do texto "propriamente dita" (linguística do sentido).

A herança de Coseriu para os estudos do texto é muito rica, e impressiona pela lógica e pela profundidade das ideias, mas muitas ainda carecem de desenvovimento. Na nossa opinião, retomar as proposições Coseriu e estabelecer diálogos com os estudos atuais constituem um empreendimento fundamental para a ampliação e o aprofundamento dos estudos do texto.

\section{Referências}

ASCHENBERG, Heidi. Subjetivité et objectivité dans la pensée de Coseriu. In: GÉRARD, Christophe et MISSIRE, Régis (eds). Eugenio Coseriu aujourd'hui linguistique et philosophie du langage. Limoges: Lambert-Lucas, 2015, p. 195-206.

CAVAlCANTE, Mônica M.; PINHEIRO, Clemilton L.; LINS, Maria da Penha P.; LIMA, Geralda. Dimensões textuais nas perspectivas sociocognitiva e interacional. In: BENTES, Anna C.; LEITE, Marli Q. (Orgs.). Linguística de texto e Análise da conversação: panorama das pesquisas no Brasil. São Paulo: Cortez, 2010, p. 225-261.

CAVALCANTE, Mônica M., CUSTÓDIO FILHO, Valdinar. Revisitanto o estatuto do texto. Revista do Gelne, v.2, n. 12, 2010, p. 56-71.

CAVAlCANTE, Mônica M. et al. (orgs.). Programação e resumos. I Simpósio de Linguística Textual. Fortaleza: PROTEXTO/UFC, 2015.

CAVAlCANTE, Mônica M., BRITO, Mariza A. P., CUSTÓDIO FILHO, Valdinar, SILVA, Valney V. da. Desafios da Linguística Textual no Brasil. Intersecções, edição 18, ano 9, número 1, 2016, p. 7-25.

COSERIU, Eugenio. Teoria da linguagem e lingüística geral: cinco estudos. Rio de Janeiro: Presença; São Paulo: Edusp, 1979.

COSERIU, Eugenio. Textlinguistik: Eine Einführung. Hrsg und beab. Von Jörn Albrecht. Tübingen: Francke, 1980.

COSERIU, Eugenio. Linguistica del testo: Introduzione a una ermeneutica del senso. Edizione italiana a cura di Donatella Di Cesare. Roma: Caroci editore, 1997.COSERIU, Eugenio. Lingüística del texto. Introducción a la hermenéutica del sentido. Édition et annotation d'Oscar Loureda Lamas. Madrid: Arco/Libros, 2007.

JUBRAN, Clélia. C. A. S. A Perspectiva textual-interativa. In: JUBRAN, Clélia. C. A. S. e KOCH, Ingedore G. V. (Orgs.). Gramática do português falado culto falado no Brasil - a construção do texto falado. v. I. Campinas: Editora da UNICAMP, 2006, 2736. 
JUBRAN, Clélia C. A. S. Uma gramática textual de orientação interacional. In: CSTILHO, Ataliba T. de; MORAIS, Maria A. Torres; LOPES, Ruth E. Vasconcelos e CYRINO, Sônia M. Lazzarini (Orgs.). Descrição, História e Aquisição do Português Brasileiro. São Paulo: Fapesp, Campinas: Pontes Editores, 2007, p. 313-327.

JUBRAN, Clélia. C. A. S. e KOCH, Ingedore G. V. (Orgs.). Gramática do português falado culto falado no Brasil - a construção do texto falado. v. I. Campinas: Editora da UNICAMP, 2006.

KOCH, Ingedore G. V. Introdução à Linguística Textual: trajetória e grandes temas. São Paulo: Martins Fontes, 2004.

LAMAS, Óscar L. Presentación del editor: La Textlinguistil de Eugenio Coseriu. In: COSERIU, Eugenio. Lingüística del texto. Introducción a la hermenéutica del sentido. Édition et annotation d'Oscar Loureda Lamas. Madrid: Arco/Libros, 2007, p. 19-73.

MATOS, Janaica G., BRITO, Mariza A. P., CAVALCANTE, Mônica M. O entrelaçamento de referentes nas recategorizações em piadas: qual o papel das cadeias referenciais? Calidoscópio, Vol. 14, n. 3, 2016, p. 499-508.

PINHEIRO, Clemilton L. Estratégias textuais-interativas: a articulação tópica. Maceió: EDUFAL, 2005.

Recebido em 13/03/2018. Aceito em 02/06/2018. 